\title{
The Statutory Registration of Psychotherapists?
}

\author{
By Michael Shepherd, Professor of Epidemiological Psychiatry, Institute of Psychiatry
}

Based on a discussion paper which was read at the recent Annual Meeting, July 1980. (A report of the session appears in this issue on page 170.)

The Report of the Professions Joint Working Party (1978) raises a number of questions. The first of these springs from the composition of the Working Party. Five of the organizations are overtly in business to train and certify practitioners of psychotherapy along psychodynamic lines, but though the Report speaks collectively of 'seven organizations representing practitioners of psychotherapy' neither the British Association for Behaviour Psychotherapy nor the Royal College of Psychiatrists can be categorized in the same way. Each of these organizations raises issues of a different order.

Concerning the Note of Dissent by the British Association for Behavioural Psychotherapy the foreword to the Report comments that the only major question on which the Working Party was unable to agree was the nature of the qualifications required for registration as a psychotherapist. A glance at the wording shows this to be an understatement: 'there is no general agreement as yet on what constitutes a valid psychotherapeutic training, nor is there good evidence that patients benefit from treatment by most qualified psychotherapists ... That some professional groups approve training courses is of little help to the public until it has been shown that the psychotherapy which is the subject of such courses in fact benefits patients'.

The interest of behavioural psychiatrists in psychothera peutic procedures can hardly be expected to coincide with those of the other organizations devoted to psychotherapy. As Franks and Wilson (1980) have pointed out, '... behaviour therapy and psychodynamic psychotherapy are fundamentally incompatible at the conceptual level and ... integration at this level is disadvantageous to both'. In the present context this disagreement about the nature of psychotherapy is brought into a still wider perspective by the fact that the British Psychological Society did not seek membership of the Working Party, preferring instead to send an observer. In an open letter to the Department of Health and Social Security the BPS (1978) made its position explicit: '.. any form of functional registration of psychotherapists would be impossible owing to the indefinable and imprecise nature of the activity and the legitimate involvement of many professional groups; we question the feasibility of an indicative form of registration of practitioners of this indefinable function, as logically it would require a never-ending list of additional protected names and titles ... we regard psychotherapy as one of a range of skills carried out within established and well-regulated professions such as medicine, psychology and nursing. In this situation we see the standards and controls of psychotherapy as being regulated by the primary profession'.
Such views might have been expected to echo opinion from the Royal College of Psychiatrists. Their spirit, indeed, was expressed by the College in its memorandum published as a reply to the DHSS on the Foster Report (1972), when it even went on to recommend that 'all properly qualified lay psychotherapists should work under medical aegis, and be under obligation to report at regular intervals to a medical supervisor who should take ultimate responsibility for the treatment'. This is a far cry from the statement in the Working Party's Report that 'medicine is one of the fields adjoining psychotherapy', a comment which may be put alongside Sir John Foster's notion, reiterated in the Report, of psychotherapy as being virtually synonymous with psychological medicine. Neither this issue nor its congeners, however, were raised by the representative of the College, which appears therefore to have endorsed the recommendations as they stand, as might befit an organization 'representing practitioners of psychotherapy' but hardly a body with the aims and structure of the College.

Fortunately, since the Report is intended to be no more than a discussion paper, I may properly raise some of the wider issues for public comment with particular reference to other implications for the College. Much of the argument hitherto has been conducted as part of what is often politely termed medico-political debate. One of the major objectives of such debate has been expressed indelicately but bluntly by one of our political masters as the determination of whose snout goes into the trough. Understandably important though this may be, I would suggest that as a learned society the College must be at least as concerned with the nature of the fodder in the trough, a concern which would lead inescapably to the nature of psychotherapy itself, or at least of psychotherapy as it appears in the Foster Report (1971), where it is invoked in an attempt to grapple with the complex and difficult issues raised by the practice and efiects of scientology. Scientologists, Foster argues, claim to be psychotherapists, but the criteria of psychological medicine, as he calls it, should be those which come within the accepted framework and ethos of an established professional group. But what does he mean by psychotherapy? Sir John is evidently a most competent lawyer, but his knowledge of medical history is rather less secure, for he asserts of psychotherapy that "its origin as a treatment for the relief of illness is to be found with Professor Sigmund Freud'. Much of his argument clearly rests on psychoanalytical theory and practice and, of course, on the assumption that psychotherapy is a potentially effective form of treatment.

Such views are not peculiar to this country. In particular, 
they have recently become the subject of intense interest in the United States where, since the last war, psychotherapeutics have come closer to being identified with psychological medicine than anywhere else. After a full generation of so-called dynamic psychiatry, however, there has been a sharp swing of opinion expressed about both the form and the practice of this approach to the subject and in particular about the efficacy of psychotherapeutic methods of treatment (Shepherd, 1979). The debate has been intensified recently with the prospect of the introduction of some form of health insurance, with its attendant spectres of accountability and the taxpayer's dollar (Astrachan et al, 1976). The subject was examined two years ago by the Presidential Commission on Mental Health and is currently under scrutiny by a Senate Finance Committee. Dr Gerald Klerman, the administrator of the Federal Government's Alcohol, Drug and Mental Health Administration has already stated that the current principle for reimbursement, i.e. usual and customary practice, will have to be replaced by the criteria of efficacy and of safety (Herrington, 1980).

Efficacy and safety: what is the evidence for either? Unsatisfactory, it seems, on both counts. On the question of outcome, the most impressive study to date is that of Smith and Glass (1977), who carried out a careful review of some 400 controlled evaluations of psychotherapy and counselling by the technique of meta-analysis, the integration of research through statistical analysis of the analyses of individual studies. To meet the criteria of inclusion, they defined psychotherapy as 'the informed application of techniques derived from established psychological principles by persons qualified through training and experience to understand these principles and to apply these techniques with the intention of assisting individuals to modify such personal characteristics as feelings, values, attitudes and behaviours which are judged by the therapist to be maladaptive or maladjustive'.

The outcome of treatment was assessed for the following 10 types of psychotherapy: psychodynamic, eclectic, Adlerian, transactional, rational-emotive, gestalt, clientcentred, implosion, systematic desensitization and behaviour modification. Two principal results emerged. First, there was small but definite advantage associated with the psychotherapeutic procedures when compared with either a placebo or no treatment. And, secondly: 'Despite volumes devoted to the theoretical differences among different schools of psychotherapy, the results of research demonstrate negligible differences in the effects produced by different therapy types. Unconditional judgements of superiority of one type or another of psychotherapy and all that these claims imply about treatment and training policy are unjustified'.

On the issue of safety, Glass and Singer have nothing to say about the adverse effects of psychotherapy. This topic has been curiously neglected in the literature, but it is now apparent that the potentially deleterious effects of psychotherapy call for serious consideration (Lambert et al, 1976).

This intense concern with psychotherapy has inevitably brought our American colleagues up against the same issues concerning professional regulation. How much more thoroughly they have examined them may be gathered from a major publication on the subject, a scholarly four-volume series on the Regulation of Psychotherapists by Daniel Hogan, a legally trained social scientist in the Department of Psychology and Social Relations at Harvard University, containing a source bibliography of more than 3,000 references, a handbook of state licensure laws, a review of malpractice suits in the US and a whole volume devoted to the philosophy and practice of professional regulation (Hogan 1980). Here Hogan provides a searching overview of the nature and variants of psychotherapy which, he argues with some force, must include such exotic activities as bioenergetics, encounter groups, est, life-planning laboratories and psychodrama. Despite massive attempts to protect the public by legislation the current situation remains unsatisfactory, and Hogan's conclusion is unequivocal: 'restrictive licensing laws are only advisable when a professional field is clearly defined and a consensus has been reached based on sound scientific evidence as to the standards and criteria appropriate for determining who is qualified to practise. In other words, the profession must be fully mature before restrictive licensing is advisable. Psychotherapy has not yet achieved this status'. Accordingly, Hogan argues his way through the dense thicket of American law on professional regulation which, he proposes, calls for re-appraisal so as to enable control to be replaced by a much looser system which he calls 'the facilitation of interaction'.

Here, then, is one theme which invites exploration. But there is another, at least as important in the conditions of the National Health Service, which calls for further consideration. This points towards the complex issues attendant on cost and accountability in relation to ill-defined procedures which are of uncertain value and carry potential hazards. In his original definition of psychotherapy Sir John Foster includes the clause, 'for reward', which is nowhere questioned in the Working Party's Report. However, as the BMA emphasized in commenting to the Department on the Foster Report:- 'The question of fee or reward has no place in the definition of psychotherapy' (BMA, 1972). Further, the Royal College of Psychiatrists, having been asked specifically by the Department whether any control should be restricted to the practice of psychotherapy for reward, originally stated its "hope that the Statutory Body would examine the position of those who practise psychotherapy within the National Health Service and other recognized fields and institutions, where problems also exist' (Memorandum, 1972).

Exist they certainly do, though there is no mention of them in the Report. Within the framework of a publicly financed health service, as Professor Cochrane has argued so insistently (1972), any form of treatment-and 'psychotherapy' lays claim to being such-must satisfy stringent criteria of both efficacy and evaluation for the sake of the 
taxpayer as well as the profession. Unfortunately, the equivocal evidence on efficacy has hitherto weighed little with representatives of the global psychodynamic approach to mental disorder which, in the words of the Society of Clinical Psychiatrists, 'should provide the theoretical and practical basis not only for psychiatry but for the whole of medical practice' (Society of Clinical Psychiatrists, 1970) and, still further, can furnish as a philosophy for the caring professions what Dr Sutherland calls a 'psychodynamic image of man' (Sutherland, 1980).

The same assumption underlies the opinions of less outspoken sympathizers like Professor Hill, who tend to shift the emphasis from practice to education: 'I do not believe that there will ever be a formal place for formal psychoanalysis as a therapeutic service within the NHS, but there will be a great need for psychiatrists and also non-medical professional persons who are trained analysts ... not to provide a service but to teach others to do so more effectively' (Hill, 1969). According to this view, the basis of the contribution provided by such workers resides in the concept of 'psychological understanding', on which psychotherapeutic skills are said to depend. The precise meaning of this term is difficult to ascertain, but no-one familiar with David Hume's famous analysis of the limitations of human understanding in the Enquiry can fail to wonder whether so fragile a faculty could bear so heavy a burden. At least two other British professors of psychiatry have entertained explicit reservations. Professor Cawley is on record as having challenged the College statement on the role of psychotherapy: 'The Royal College's document urges that everything that comes under the broad heading of psychotherapy is the province of the specialist psychotherapist. He is evidently the person to teach all psychotherapy, either directly or by proxy. This policy is neither feasible nor desirable' (Cawley, 1971). Professor Kessel (1980) goes further: '.. . the psychotherapists who control the training programmes approved by the Royal College of Psychiatrists insist dogmatically that trainees for consultant psychotherapy posts must have some personal experience of therapy. I hope the College, and the Association of University Teachers of Psychiatry which also has an interest but has supinely acquiesced so far, will soon find the courage and the decency to resist that impertinence. It is not part of the liberal tradition of British universities to compel a man to explore his own complexes in order to receive education or training.'

I mention such individual views not only because of their relevance to the topic under discussion but because they exemplify an evident division of opinion within the College. This may be due to no more than a vigorous tail wagging a rather inert body or it may reflect a more deep-seated malaise. It came to the surface clearly enough at the last Conference on Postgraduate Psychiatric Education, when the present President of the College was taken to task by the then Registrar of the RMPA for proposing that so much time be devoted to psychotherapy; another contributor drew attention to the 'Trojan horse' method of invading the curriculum; and $\mathrm{Dr}$ Wolff is on record as follows: 'Having listened to the group, I feel I should say something therapeutic - but this is almost impossible'.

Perhaps it is time that the College mounted a serious assault on the almost impossible. If it does so it will, I suspect, find that it is dealing not only with legal, professional and scientific issues but also with the medical end of the pastoral and thaumaturgic spectrum. But at least it will come to grips with the central problems instead of lending its name to a report which should, in my view, be regarded as initiating rather than concluding a discussion which is long overdue. If it does not take up the challenge, there can be no complaints if decisions are taken elsewhere.

\section{REFERENCES}

Astrachan, B. M., Levinson, D. J. \& Adler, D. A. (1976) The impact of National Health Insurance on the tasks and practice of psychiatry. Archives of General Psychiatry, 33.

BRmish Medical Associanon (1972) Reply to the Department of Health and Social Security concerning the Foster Report on Scientology. British Medical Journal Supplement, vol. i, 13 May, 114-5.

Brmish Psychological Society (1978) Letter to the DHSS. Bulletin of the British Psychological Society, October, pp 369 . 70.

CAwLEY, R. H. (1976) The Teaching of Psychotherapy. Proceedings of conference held by Association of University Teachers of Psychiatry.

Cochrane, A. L. (1972) Effectiveness and Efficiency. The Nuffield Provincial Hospitals Trust.

Foster, J. G. (1971) Enquiny into the Practice and Effects of Scientology. London HMSO.

FrANKs, C. M. \& WILSON, G. T. (1980) Behaviour therapy: an overview. In Annual Review of Behaviour Therapy, Theory and Practice, (eds. C. M. Franks and G. T. Wilson), Vol. 7, pp 32-33. New York: Brunner/Mazel.

HerRington, B. S. (1980) Congress asks: does therapy work? Psychiatric News, 6, p 1.

HILL, D. (1969) Psychiatry in Medicine. Nuffield Provincial Hospitals Trust.

Hogan, D. (1980) The Regulation of Psychotherapists, vol I. Cambridge, Mass: Ballinger.

Kessel, N. (1980) The nature of peychotherapy. World Medicine. 28 June, 37.8 .

Lambert, M. J., Bergan, A. E. \& Coluns, J. L. (1976) Therapistinduced deterioration in psychotherapy. In The Therapist's Contributions to Effective Treatment: an Empirical Assessment. New York: Pergamon.

Royal College of Psychiatrusts (1972) Memorandum. News and Notes, British Journal of Psychiatry, July, pp 4-6.

ShePherd, M. (1979) Psychoanalysis, psychotherapy, and the health services. British Medical Journal, ii, 1557-59.

SMrTH M. L. \& GLASS G. V. (1977) Meta-analysis of psychotherapy outcome studies. American Psychologist, vol 32, 752-60.

Society of Cunical Psychiatrists (1970) The Place of Dymamic Psychiatry in Medicine: Report of a Study Group, p 7. 